\title{
De la Rose. Texte, Image, Fortune, Études publiées par Catherine Bel et Herman Braet
}

\section{Maria Colombo Timelli}

\section{(2) OpenEdition}

1 Journals

Édition électronique

URL : http://journals.openedition.org/studifrancesi/8827

DOI : 10.4000/studifrancesi.8827

ISSN : 2427-5856

Éditeur

Rosenberg \& Sellier

\section{Édition imprimée}

Date de publication : 1 octobre 2008

Pagination : 431-432

ISSN : 0039-2944

\section{Référence électronique}

Maria Colombo Timelli, « De la Rose. Texte, Image, Fortune, Études publiées par Catherine Bel et Herman Braet », Studi Francesi [En ligne], 155 (LII | II) | 2008, mis en ligne le 30 novembre 2015, consulté le 12 janvier 2021. URL : http://journals.openedition.org/studifrancesi/8827 ; DOI : https:// doi.org/10.4000/studifrancesi.8827

Ce document a été généré automatiquement le 12 janvier 2021.

\section{(c) (i) $\odot$}

Studi Francesi è distribuita con Licenza Creative Commons Attribuzione - Non commerciale - Non opere derivate 4.0 Internazionale. 


\title{
De la Rose. Texte, Image, Fortune, Études publiées par Catherine Bel et Herman Braet
}

\author{
Maria Colombo Timelli
}

\section{RÉFÉRENCE}

De la Rose. Texte, Image, Fortune, Études publiées par Catherine BEL et Herman BRAET, Louvain-Paris-Dudley, MA, Peeters, 2006 («Synthema», 3).

1 Nous rendons compte ici des contributions concernant la littérature proprement médiévale, en renvoyant le lecteur à la section «Quattrocento» pour d'autres notices.

2 Douglas Kelly (Les visions du Paradis chez Jean de Meun et Alain de Lille: contraires choses? pp. 3-20) propose une analyse intertextuelle entre le Roman de la Rose et le De planctu Naturae pour ce qui est du personnage de Genius, et l'Anticlaudianus pour ce qui concerne les descriptions du Paradis céleste et profane.

3 Brigitte L. CAllay (Jean de Meun's "Romance of the Rose" and the Polemic on the Theological Method: a Key to Meaning? pp. 21-40) situe l'œuvre de Jean de Meun au sein du débat théologique des années 1240-1250, en soulignant en particulier le rôle de Faus Semblant, reflet des prises de position de l'auteur.

4 sylvua нUот (Women and 'Woman' in Bodley, Douce 332 (c. 1400): A Case of 'Accidental Meaning'? pp. 41-57). Le manuscrit objet de cette étude, contemporain de la Querelle sur le Roman de la Rose, contient une version amplifiée de la section due à Guillaume de Lorris et une interpolation importante dans la partie de Jean de Meun. Le programme iconographique lui-même, en partie indépendant de la tradition, encourage par ailleurs une lecture particulière du texte.

5 Alexandre LEUPIN (L'hérésie littéraire. Paradigmes textuels dans le 'Roman de la Rose', pp. 59-80) propose d'appliquer au Roman de la Rose la structure moebienne de l'exégèse 
médiévale, selon laquelle la partie attribuée à Guillaume de Lorris annoncerait celle de Jean de Meun. Par ailleurs, à la lumière des énoncés de Lacan, le véritable objet du Roman serait l'impossibilité de représenter la féminité par le langage.

6 Selon Jacek KoWALSKI (Le château de Jalousie: du rêve à la réalité, pp. 81-90), le château de Jalousie pourrait avoir constitué le modèle littéraire pour la réintroduction de la tour dans l'architecture du XIV ${ }^{e}$ siècle, et en particulier pour la construction de l'ensemble du château de Vincennes vers 1370.

Martine MEUWESE (Roses, Ruse and Romance. Iconographic Relationship between the "Roman de la Rose" and Arthurian Literature, pp. 93-116) étudie les influences réciproques entre l'illustration du Roman de la Rose et du Lancelot en prose. Parmi les éléments communs aux deux traditions iconographiques, c'est bien évidemment la rose, métaphore de la dame ou symbole de virginité, qui s'impose comme le plus significatif. Gregor WEYER, The "Roman de la Rose" Manuscript in Düsseldorf, pp. 117-140: il s'agit du ms. 2 de l'Académie des Arts de Düsseldorf, contenant une copie complète et illustrée du Roman de la Rose (29 enluminures). G.W. examine les particularités de ce cycle iconographique et, en accord avec R. et M. Rouse, attribue le premier groupe à Jeanne de Montbaston, le second à un peintre plus jeune du même atelier parisien.

Heidrun ost (The 'Mythographical Images' in the "Roman de la Rose" of Valencia, Biblioteca Histórica de la Universitat, ms. 387, pp. 141-181) étudie en particulier quatre des somptueuses enluminures qui enrichissent ce codex, appartenu entre autres à Jacques d'Armagnac. Ces illustrations, qui se rapportent au mythe de la fin de l'âge d'or avec le règne de Jupiter, révèlent des analogies remarquables avec les manuscrits de l'ovidius moralizatus de Pierre Bersuire, de l'Ovide moralisé, et du De formis figurisque deorum, et offrent un témoignage intéressant de la réception de l'Antiquité classique à la fin du Moyen Âge.

10 En reprenant les interprétations de K. Gourlay (1997) et de M.-E. Bruel, Dulce M. GONZALEZ DORESTE relève dans la célèbre tapisserie de la Dame à la Licorne l'influence du Roman de la Rose, et en particulier des analogies avec les enluminures du manuscrit de Valence, composé vers la fin du XIV ${ }^{\mathrm{e}}$ siècle dans un atelier du Nord de la France ( $\mathrm{Du}$ "Roman de la Rose"à "La Dame à la Licorne": à propos de certains détails iconographiques du ms. 387 de la B.U. de Valence, pp. 183-205).

11 Lori WALTERS consacre un long article à l'iconographie, extraordinaire à maints égards, du manuscrit conservé à Tournai (B.M. 101), dont les deux premières illustrations représentent les commanditaires ou propriétaires du codex et la Vierge. Une étude détaillée de l'ensemble montre comment le Roman de la Rose a pu être rattaché à la dévotion mariale et faire l'objet d'une lecture didactique qui en fait, sinon un 'miroir des dames', au moins un modèle de vie familiale (Marian Devotion in the Tournai 'Rose': from the Monastery to the Household, pp. 207-270).

12 Luciano Rossi (De Jean Chopinel à Durante: la série "Roman de la Rose" - "Fiore", pp. 273-298). Article en trois volets, où sont produits premièrement des documents attestant la formation juridique de Jean de Meun et son séjour à Bologne dans les années 1264-69. Suit une réflexion sur les modèles philosophiques utilisés par Jean de Meun et sur la célèbre transition entre la première et la seconde partie du Roman. Enfin, L.R. rediscute les preuves qui permettent d'attribuer le Fiore, remaniement toscan du Roman de la Rose, à Dante. 
13 Auteur d'une thèse sur le remaniement du Roman de la Rose par Gui de Mori (fin du XIII ${ }^{\mathrm{e}}$ siècle), Andrea VALENTINI examine ici quelques variantes significatives des manuscrits de Tournai, Paris (BnF, fr. 797) et Copenhague. Les liens entre les deux premiers sont sûrs, même s'il n'existe pas de preuve que leur proximité soit due à un ancêtre commun. Des trois témoins, c'est l'exemplaire de Tournai, le seul à signaler les interventions du remanieur, qui doit être choisi comme manuscrit de base pour l'édition, en préparation par le même A.V. (Le remaniement de Gui de Mori et sa tradition manuscrite, pp. 299-320).

14 Peter DE WILDE (Rencontres: le "Pèlerinage de vie humaine" et le "Roman de la Rose", pp. 321-330) décèle dans l'œuvre de Guillaume de Digulleville des traces du Roman de la Rose, qui consistent essentiellement dans l'emploi mnémotechnique de l'allégorie.

15 Yvan G. LEPAGE (La réception du "Roman de la Rose" dans les manuels et les anthologies des xix et $\mathrm{xx}^{e}$ siècles, pp. 435-454) passe en revue une quarantaine de manuels et une trentaine d'anthologies (de 1870 à la fin du xxe siècle), en mettant en rapport les résultats de la recherche érudite avec le contenu des ouvrages destinés aux étudiants, et en soulignant la réhabilitation du Roman de la Rose à partir des années 1960 seulement.

Le volume est complété par une mise à jour bibliographique portant sur les années 1990-2005 (quelque 400 titres), un index, une liste des manuscrits du Roman de la Rose, une liste des autres mss. cités. 